\title{
Hacia una fenomenología del Cántico Espiritual de San Juan de la Cruz. Directrices hermenéuticas del prólogo y la anotación
}

\author{
Lucero GONZÁLEZ SuÁREZ \\ Universidad Nacional Autónoma de México \\ noche_oscura27@yahoo.com.mx
}

\begin{abstract}
RESUMEN
Asumiendo junto con Heidegger que la filosofía es ontología por su objeto y fenomenología por su método, la intención es presentar algunas directrices para la hermenéutica de la poesía mística; específicamente para el Cántico Espiritual. Para ello se realiza una descripción esencial de la poesía, destinada a esclarecer por qué ésta es lo hablado puro, seguida por la caracterización de la poesía mística. Posteriormente se muestra que la inefabilidad de la poesía mística es un rasgo que le pertenece por ser ésta palabra originaria que funda un modo de ser en el mundo, cuyo sentido es la unión entre el hombre y Dios. Por último, atendiendo a las advertencias que San Juan de la Cruz (SJC) hace sobre la interpretación de los textos místicos, se piensa sobre el temple de la conversión como disposición emocional instalado en la cual el hombre comienza la búsqueda del Amado.
\end{abstract}

Palabras clave: poesía, mística, San Juan de la Cruz, fenomenología, hermenéutica.

\section{Toward a phenomenology of San Juan de la Cruz, Spiritual Canticle. Hermeneutical guidelines of the prologue and the annotation}

\begin{abstract}
Assuming along with Heidegger that philosophy is ontology of its object and phenomenology by its method, the intention is to present some guidelines for the hermeneutics of mystical poetry; specifically for the Cántico Espiritual. For this purpose, a description is essential to poetry, intended to clarify why this is so pure spoken, followed by the characterization of mystical poetry. Later I show that the ineffability of mystical poetry is a feature that belongs because this is original word that establishes a way of being in the world, whose meaning is the union between man and God. Finally, in response to warnings that St. John of the Cross makes in the prologue and the annotation on the interpretation of mystical texts, I think about the conversion temple as emotional disposition installed in which he begins the search for the Beloved.
\end{abstract}

Keywords: poetry, mysticism, St. John of the Cross, phenomenology, hermeneutics.

SUMARIO: 1. Introducción. 2. El poema: lo hablado puro. 3. La inefabilidad de la experiencia mística, advertencia central del prólogo. 4. Análisis fenomenológico de la anotación. 5. Conclusión. 


\section{INTRODUCCIÓN}

Las principales teorizaciones filosóficas sobre el origen y finalidad del lenguaje, de donde proceden los desarrollos ulteriores, salvo quizás los planteamientos de la analítica, son las teorías convencionalista y naturalista, que Platón reduce al absurdo en Cratilo o del Lenguaje; así como la teoría aristotélico-tomista de acuerdo con la cual los términos son signos de las pasiones del alma. De acuerdo con ambas teorías, el lenguaje es atributo esencial del alma racional. Por ello, cualquier intento de dilucidación del habla ha de tener lugar en el marco del tratado sobre el alma, la retórica o la lógica, según sea la perspectiva que se adopte. Ha de circunscribirse a la antropología, pero no a la filosofía primera.

Por su parte, a fin de mostrar la divinidad de Cristo y su identidad esencial con el Padre, el Evangelio según San Juan, afirma el origen divino de la Palabra: «En el principio existía la Palabra, la Palabra estaba junto a Dios, y la Palabra era Dios. $\rangle^{1}$ Animada por dicho propósito, la filosofía cristiana desarrolló una filosofía del lenguaje que permite reconocer en la palabra una capacidad para manifestar, poner a la luz y expresar o hacer visible el ser en su verdad, con lo cual no sólo se intenta liberar a la pregunta originaria de las ataduras lógicas y racionales, sino que se eliminan también las limitaciones de una descripción exclusivamente lógica del habla.

Frente a tales reducciones, Heidegger es el primero que se pregunta por el ser del lenguaje, sin considerarlo atributo humano ni divino, y señala la necesidad de dilucidar la esencia del habla desde ella misma. Proyecto al que alude cuando declara su propósito de «llevar el habla al habla en tanto que tal habla», para dar a entender que originaria y propiamente no es el hombre sino el ser el que habla; que sólo como escucha y resonancia del logos pre-ontológico, el existente es capaz de hablar con propiedad.

Tomando como punto de partida la afirmación heideggeriana de que «el poema es lo hablado puro», esta meditación tiene un doble propósito. Por un lado, en ella se aborda el vínculo entre habitar poético, apertura de lo sagrado y acontecimiento de lo divino, que da origen al proceso místico, del que la poesía sanjuanista es una expresión destacada. Por otro lado, su intención es posibilitar una meditación filosófica sobre el Cántico Espiritual que, en conformidad con el método fenomenológico, tome del mismo texto místico las directrices que han de regir su interpretación, para arribar a una ontología del amor místico.

El camino a seguir es el siguiente: 1 . Se parte de la descripción esencial de la poesía, así como de la poesía mística. 2. A propósito de las palabras de San Juan de la Cruz, expresadas en el prólogo del Cántico Espiritual, se aclara por qué la inefabilidad de la poesía mística es consecuencia del carácter abismático y misterioso de lo divino. 3. Para responder a la pregunta ¿A dónde te escondiste, Amado?, después de explorar la creación, el otro y el sí mismos como posibles ámbitos del ocultamiento divino, se aclara por qué, según lo dicho por SJC en la anotación del poema místico, el lugar donde el espiritual ha de buscar el rostro del Amado es ante todo la experiencia personal. La me-

${ }^{1} \mathrm{Jn}, 1,1$. 
ditación está centrada en los rasgos constitutivos del temple propio de la conversión, como un viraje existencial que señala el ingreso en el umbral de lo sagrado.

La originalidad e importancia de estas páginas reside en su que, a diferencia de las aproximaciones teológicas o psicológicas, e incluso de los acercamientos que, influenciados por el método comparativo, pretenden imponer desde fuera una perspectiva para la interpretación de los testimonios místicos, mi intención es postular un conjunto de directrices hermenéuticas, que tienen su origen en la experiencia mística.

\section{EL POEMA: LO HABLADO PURO}

En El camino al habla, luego de apuntar que la pregunta por la esencia del habla no ha sido siquiera formulada, y de exponer las razones de su olvido por parte de la tradición filosófica, Heidegger plantea la pregunta por la esencia del habla (sentido de lo que se pregunta), para lo cual pone la mira en aquella modalidad que considera más originaria, a saber, la poesía.

si debemos buscar el hablar del habla en lo hablado, debemos encontrar un hablado puro en lugar de tomar indiscriminadamente un hablado cualquiera [v.g., el parloteo de la publicidad o las habladurías del chisme que hacen eco de voces anónimas]. Un hablado puro es aquel que desde la perfección del hablar, propio de lo hablado, se configura como perfección iniciante. Lo hablado puro es el poema. ${ }^{2}$

El habla no es la actualización de una facultad humana; es la mostración velada de la verdad del ser en su despliegue histórico. El existente sólo habla propiamente cuando se torna eco del decir del ser; cuando a través suyo se consuma la manifestación histórica del sentido ontológico como evento. El poema es lo hablado puro porque en él se resguarda y salva del olvido el eco de una experiencia originaria, aunque pre-ontológica y no tematizada, de su ser en el mundo, compartido con los otros. La poesía es palabra inicial; es la manifestación articulada de la apertura esencial del existente a sí mismo, a los entes intramundanos y a los otros -a lo cual agregaría yo que también lo es del encuentro con aquello lo totalmente Otro. ${ }^{3}$

El poema es la palabra en la que se expresa el habitar poético. El habitar poético es la disposición existencial abierta a la espontaneidad de los fenómenos, que se deja embargar por la donación de su sentido. «Sentido es aquello en que se apoya el 'esta-

\footnotetext{
${ }^{2}$ M. Heidegger, El camino al habla (trad. esp., Yves Zimmermann), Serbal, Barcelona, 1990, p. 14.

${ }^{3}$ Lo «totalmente Otro» es la categoría acuñada por Rudolf Otto para referirse al ser trascendente de lo numinoso. En tanto que mysterium, lo numinoso se distingue de cualquier otro fenómeno por ser lo totalmente Otro, es decir, lo enteramente distinto respecto de cualquier otro objeto de experiencia cotidiana. Asimismo, lo numinoso es mysterium tremendum, toda vez que se presenta como poder avasallador que atemoriza. Por último, lo numinoso es fascinans por su capacidad para seducir y atraer por completo la atención de la conciencia relligiosa. Para una presentación detallada del concepto, véase: R. Otto, Lo santo. Lo racional y lo irracional en la idea de Dios, Alianza Editorial, Madrid, 1996.
} 
do de comprensible' de algo. Lo articulable en el abrir comprensor es lo que llamamos sentido.» ${ }^{4}$ Comprender originariamente una presencia intramundana, un fenómeno, es descubrirla a una con el propio ser, sin que por ello se entienda que tenga lugar una reflexión formal al respecto. Comprender es descubrir el sentido de lo que se muestra; su verdad. La poesía es aquella modalidad del comprender donde se resguarda, en su ocultamiento, la manifestación esencial del ser: el ser en su verdad y la verdad del ser. La poesía es uno de los abrigos del ser, donde la verdad de lo que sólo se muestra veladamente (el ser) perdura en su misterio. Como Heidegger sostiene, «El habla [poética] habla en tanto que son del silencio» ${ }^{5}$; conduce a la resonancia de la palabra el acaecer de una experiencia de encuentro entre el existente y algún ámbito de sentido ontológico.

\section{LA INEFABILIDAD DE LA EXPERIENCIA MÍSTICA, ADVERTENCIA CENTRAL DEL PRÓLOGO}

La palabra poética se torna canción o cántico místico cuando es resonancia de alguna manifestación esencial de lo divino. «Cántico espiritual» y «canción mística» nombran la palabra que expresa el encuentro, gracias al cual se da la apropiación del sentido salvador de lo divino y, a la par, la apropiación por parte del existente de su ser para Dios; de la dimensión existencial que lo hace capaz de abrirse y disponerse favorablemente a dicha experiencia. La poesía mística es la respuesta sonora del existente, originada por la mostración silenciosa de lo divino.

La incapacidad para unirse espontáneamente con lo divino explica el surgimiento de la religión como sistema de mediaciones. Las mediaciones son principalmente de dos tipos: hierofanías y misteriofanías. El término «hierofanía», debido a por Mircea Eliade, nombra al «objeto del mundo que, sin dejar de ser lo que es, hace presente la realidad del Misterio para el hombre. $»^{6}$ Por su parte, el término «misteriofanías», propio de la fenomenología contemporánea desarollada por José Gómez Caffarena y Juan Martín Velasco, designa ciertas «realidades visibles del mundo religioso [...] que hacen posible la relación entre el Misterio [...] y el ser humano [...] «mediando» la presencia inobjetiva del Misterio en el mundo de los objetos. $\rangle^{7}$ La categoría fenomenológica Misterio Salvífico designa la esencia analógica de lo divino, despojada de su representación personal o impersonal, monista o dualista, trascendente o inmanente. La realidad que ella mienta es el centro y origen de la vida religiosa y mística, en torno al cual se articulan los diversos aspectos del fenómeno correspondiente. ${ }^{8}$ p. 169 .

${ }^{4}$ M. Heidegger, El Ser y el Tiempo, (trad. esp. José Gaos), Fondo de Cultura Económica, México, 1988,

${ }^{5}$ M. Heidegger, El camino al habla, op. cit., p. 27.

${ }^{6}$ Velasco, Juan Martín, Introducción a la Fenomenología de la Religión, Trotta, Madrid, 2006, p. 196.

${ }^{7}$ Idem.

${ }^{8}$ Dicha categoría nombra el «primer analogado» que la historia comparada de las religiones postula como hipótesis de investigación. Su sentido último no es ontológico sino metodológico. El «Misterio Salvífico» denomina 
Tanto las hierofanías como las misteriofanías median la presencia del Misterio Salvífico. Mas para que a través de ellas lo divino le «hable» al existente, es necesario que este último se familiarice con el sentido histórico-cultural de aquéllas. Sin excepción, en diferentes contextos y momentos, cada una de las realidades ha sido elevada al rango de hierofanía o misteriofanía. «Misteriofanías» y «hierofanías» no son entidades de por sí sino fenómenos cuya presencia es signo y evocación de lo divino. Como cualquier otro fenómeno, la interpretación de ambas está orientada y determinada por el horizonte de pre-juicios que guían y orientan la comprensión del existente. Aquello que para un cierto pueblo y en un determinado momento es capaz de traer a la presencia lo divino, más tarde puede perder su carácter sagrado. Y esto último, no porque el sustrato material de dichas mediaciones se destruya; sino porque al caer en el olvido o cambiar de sentido éstas pierden su capacidad para evocar la presencia de lo divino y retornan al mundo de lo profano.

Para el cristianismo sanjuanista, la mediación por excelencia es el Amado Esposo Cristo porque en Él lo divino se manifiesta como donación libre y graciosa que convoca al existente a la salvación mediante el seguimiento de la cruz. ${ }^{9}$ Dios crea el mundo y se encarna, a fin de ofrecer al existente la posibilidad de la salvación en el ejercicio del amor perfecto. «El Hijo de Dios vino al mundo para incorporarnos consigo y hacernos vivir de Él como Él mismo vive del Padre, a fin de que tengamos vida eterna y de que ésta se manifieste en nosotros cada vez más plenamente.. ${ }^{10}$

Como SJC advierte una y otra vez, el Dios hecho carne del cristianismo es siempre un Dios desconocido al que no puede comprenderse sino veladamente en la experiencia contemplativa, en virtud de su plenitud inabarcable. Dios «es noche oscura para el alma en esta vida.» ${ }^{11}$ Tal es la primera y principal causa de su inaccesibilidad que explica el decir paradójico, temeroso y dubitativo, de los «dichos de amor en inteligencia mística».

Si con los elementos del prólogo queremos formar una definición de la «inteligencia mística», podemos decir que «es una teología o sabiduría mística en

\footnotetext{
la comunidad funcional que vincula las prácticas religiosas histórico-concretas. A través suyo las fenomenologías de la religión y de la mística designan la esencia de lo divino (lo que hace ser tales a Dios y a los dioses) valiéndose del pensamiento analógico que procede comparativamente. El correlato de dicho concepto es una abstracción que sirve para establecer puentes de contacto entre las diversas religiosidades y espiritualidades; su referencia no es la esencia subsistente de por sí, ni el eidos de lo divino en sentido platónico.

${ }^{9}$ La donación de lo divino no es un evento que el existente pueda provocar sino un acontecimiento de carácter gratuito, al que teológicamente apunta el problema de la gracia. El existente no puede demandar ni exigir la salvación. Sólo puede disponerse favorablemente al advenimiento de la gracia, pero no puede salvarse a sí mismo ni por sus propios medios. Dicha problemática fue el origen de la disputa entre quienes afirmaron que la contemplación adquirida era suficiente para la salvación y quienes, como SJC, declararon su insuficiencia para preservar la total autonomía de Dios respecto de la labor espiritual encaminada al merecimiento de la gracia.

${ }^{10} \mathrm{~J}$. G. Arintero, La evolución mística en el desenvolvimiento y vitalidad de la Iglesia, B.A. C., Madrid, 1968, p. 3.

${ }^{11}$ San Juan de la Cruz, Subida del Monte Carmelo, libro 1, capítulo 2, párrafo 1. En adelante me referirié a esta obra mediante la sigla $\mathrm{S}$, precedida del número arábigo correspondiente al libro, posterioremente señalaré el capítulo y párrafo citados (v.g., 1S 2, 1).
} 
la cual las verdades divinas sin entenderse distintamente, no sólo se conocen, sino que al mismo tiempo se gozan o gustan, al modo de la fe en que se ama a Dios sin entenderle [agregaría yo: con la claridad y distinción de la luz natural de la razón]». ${ }^{12}$

Para el místico, ${ }^{13}$ el encuentro personal con Dios es una experiencia límite que rompe con las estructuras de su modo de estar en el mundo previo y resquebraja la representación que tiene de sí mismo por cuanto abre sus ojos a una realidad hasta entonces deseada pero jamás vista. El conocimiento amoroso de Dios, que posibilita el ejercicio del amor perfecto (fin sobrenatural del existente) es por fe, en ausencia de la luz natural de la razón. Dios no puede ser conocido por el entendimiento, la voluntad ni la memoria (facultades naturales) por que, como SJC repite una y otra vez, «todos los medios han de ser proporcionados al fin, es a saber: que han de tener alguna conveniencia y semejanza con el fin, tal que baste y sea suficiente para que por ello se pueda conseguir el fin que se pretende. $>{ }^{14}$ Dada la desproporción entre los medios que el existente tiene para conocer y el fin sobrenatural del amor perfecto, al que arriba el místico en la unión de semejanza con Dios, de ello se sigue que «ni el entendimiento con sus inteligencias podrá [entender cosa semejante a El, ni la voluntad podrá] gustar deleite y suavidad que se parezca a la que es Dios, ni la memoria pondrá en la imaginación noticias y imágenes que le representen». ${ }^{15}$

La experiencia mística es inefable porque acaece en las oscuridades de la fe teologal. De acuerdo con SJC, una de las razones por las cuales se llama noche oscura «este tránsito que hace el alma a la unión de Dios [...] por parte del medio o camino por donde ha de ir el alma a esta unión, lo cual es la fe, que es también oscura para el entendimiento como noche.» ${ }^{16} \mathrm{La}$ fe es luz sobrenatural que supera los alcances del entendimiento. Progresar en el conocimiento oscuro por fe de Dios es quedarse «sin luz (natural) y a oscuras viendo». Teología y teología mística son caminos diversos que conducen a encuentros igualmente distintos con lo divino.

Luego de atravesar por la experiencia amorosa de unión con el Esposo, llevada por su deseo de dar testimonio escrito de cuanto le ha ocurrido y consciente de los límites del lenguaje ordinario, la esposa del Cántico Espiritual pregunta: «¿quién podrá escribir lo que a las almas amorosas donde El mora hace entender?, ¿y quién podrá manifestar con palabras lo que las hace sentir?, ¿y quién finalmente lo que las hace

${ }^{12}$ E. Pacho, Vértice de la poesía y de la mística. El «Cántico Espiritual» de San Juan de la Cruz, Estudios Monte Carmelo 4 (1983) p. 54.

${ }^{13}$ Cuando hablo de experiencia mística no me refiero a fenómenos extraordinarios tales como éxtasis, raptos, hablas o visiones, sino al ímpetu amoroso que constituye la razón de ser del proceso místico, que abarca desde los principios de la búsqueda al matrimonio espiritual. Considero adecuado calificar como místico al principiante y al converso toda vez que el proyecto que orienta las acciones de ambos tiene por término el encuentro unitivo con Dios; e incluso a aquel que, desde la parálisis de la imposibilidad, busca la experiencia correspondiente en un mundo donde toda huella de su aparecer está eclipsada.

$142 \mathrm{~S} 8,2$.

$152 \mathrm{~S} 8,5$.

16 1S 2, 1 . 
desear?». ${ }^{17}$ Sus preguntas delatan la dificultad de manifestar la experiencia de la fe que otorga al existente un saber sobrenatural incomprensible para la razón; el conjunto de sensaciones que se originan en el contracto con lo totalmente Otro; y el deseo exacerbado de la presencia de su Esposo que la hace buscarlo durante la noche, estando sosegada ya la casa de sus apetitos y aficiones.

Ante la imposibilidad de comunicar a otros mediante palabras ordinarias la exhuberancia de sentido que comporta su experiencia, SJC accede a la conciencia de los límites del decir y declara: «esta es la causa por que [quienes persiguen declarar tal experiencia, lo hacen] con figuras, comparaciones y semejanzas, [y así] antes rebosan algo de lo que sienten y de la abundancia del espíritu vierten secretos y misterios que con razones lo declaran. $\rangle^{18} \mathrm{Al}$ decir esto, el poeta místico atribuye a la palabra poética que emana de la sabiduría mística la capacidad de insinuar o balbucir la manifestación del misterio de Dios, a través de figuras, comparaciones y semejanzas.

La poesía fractura el vínculo representativo entre el decir objetivador y la experiencia, porque no representa ni denota la experiencia de Dios. Porque se asemeja a una caracola marina donde retumba el eco del encuentro amoroso con Dios para que, quien sea capaz de acercarla a su oído, pueda escuchar su rumor y dejarse enamorar por la el testimonio amoroso que ella alberga.

El habitar poético supone la emergencia de un mundo específico de sentido y un modo peculiar de habérselas con lo que hace frente (entes intramundanos, los otros y lo divino). De acuerdo con Heidegger, no hay oposición entre lenguaje ordinario y poesía. «es más bien el hablar cotidiano un poema olvidado y agotado por el desgaste y del cual apenas ya se deja oír invocación alguna.» ${ }^{19}$ A pesar de ello, toda vez que la poesía es palabra inicial y el lenguaje ordinario ha perdido su carácter originario, ello explica la diferencia de sentido entre la poesía mística y su declaración doctrinal; entre SJC poeta y maestro espiritual, que él mismo tiene en mente cuando advierte: «Por haberse, pues, estas canciones compuesto en amor de abundante inteligencia mística, no se podrán declarar al justo ni mi intento será tal, sino sólo dar alguna luz general.» ${ }^{20}$ Ni siquiera el autor de ambas puede agotar el sentido de la poesía mística en la exposición doctrinal de ésta. El problema no es de traducción de unas palabras por otras, sino de irreductibilidad de los comportamientos poético y teológico ante lo divino.

no pienso yo ahora declarar toda la anchura y copia que el espíritu fecundo de el amor en ellas lleva; antes sería ignorancia pensar que los dichos de amor en inteligencia mística, cuales son los de las presentes Canciones, con alguna manera de palabras se puedan bien explicar. ${ }^{21}$

\footnotetext{
${ }_{17}$ San Juan de la Cruz, Cántico Espiritual B, Prólogo, párrafo 2. En lo sucesivo citaré esta obra mediante la siglas $\mathrm{CB}$, seguidas de la sección (prólogo, anotación o canción) y el párrafo, cuando sea el caso (v.g., CB, prólogo, 2).

${ }^{18} \mathrm{CB}$, Prólogo, 1.

${ }^{19}$ M. Heidegger, El camino al habla, op. cit., p. 28.

${ }^{20} \mathrm{CB}$, Prólogo, 2.

${ }^{21}$ Idem.
} 
Una manera de salvar la distancia entre el decir poético y el doctrinal consiste en asumir que, al declarar las canciones, SJC adopta un comportamiento diverso en cuanto a sus motivaciones, origen y finalidad, respecto del habitar poético. De ahí que, si bien se realiza con ocasión de la poesía a la que busca esclarecer a través del comentario, la declaración de las mismas no se ata a ellas. Para SJC, la riqueza de la sección poética del Cántico Espiritual radica en su apertura hermenéutica infinita.

los dichos de amor es mejor dejarlos en su anchura, para que cada uno de ellos se aproveche según su modo y caudal de espíritu, que abreviarlos a un sentido a que no se acomode todo paladar; y así, aunque en alguna manera se declaran, no hay para qué atarse a la declaración. ${ }^{22}$

\section{ANÁLISIS FENOMENOLÓGICO DE LAANOTACIÓN}

San Juan de la Cruz antepone una pequeña anotación a las canciones en la que expone lo que a mi parecer puede concebirse como la descripción fenomenológica de la disposición afectiva que señala el momento de la conversión; del vuelco de la existencia que la introduce en un camino hasta entonces inexplorado de búsqueda del Amado.

La conversión es el acontecimiento por obra del cual el sentido de la existencia se orienta a la búsqueda del encuentro con lo divino, de modo que sus pasos toman un rumbo distinto. En el caso del cristianismo, la conversión tiene lugar gracias a la manifestación amorosa del Esposo Cristo. Manifestándose como amor en gratuidad, que por amor se ha entregado a sí mismo, la presencia elusiva de Cristo provoca que el existente reflexione sobre lo que ha hecho y lo que ha dejado de hacer, asumiendo al responsabilidad de su ser para Dios.

La conversión, sea que se la entienda como un movimiento vital de la increencia a la fe, o como tránsito de la fe natural a la sobrenatural, constituye el primer encuentro auténtico con Dios. ${ }^{23}$ En cualquiera de los dos casos, las preguntar obligadas son: ¿cómo

\footnotetext{
${ }^{22}$ Idem.

${ }^{23}$ En un sentido cerrado y excluyente, puede pensarse que el existente sólo está en condiciones de ser interpelado por el acontecer del Misterio Salvífico cuando dicha búsqueda figura entre sus proyectos. Cuando permanece en estado de abierto, expectante de las mediaciones hierofánicas o misteriofánicas propias de su tradición. De manera que, cuando tiene lugar la donación de la gracia, no sólo asume la interpelación de dicho acaecer; más aun, en una mirada retrospectiva, se represente su obrar pasado como vanidad y dilapidación. Piensa y siente que la totalidad de sus obras es vana y falta de mérito frente a Dios. Tal es el caso de quien, ya ha oído hablar de Cristo, pero antes de dicho momento no había participado de su experiencia; así como de quien transita de la fe vulgar a la fe sobrenatural. Más problemático resulta el acontecer del Misterio Salvífico que se manifiesta ante aquellos cuyo proyecto vital se aparta por completo de la disposición místico-religiosa. Siempre que se piense, como hacen muchos intérpretes de la obra de SJC, que sus guías espirituales están dirigidas única y exclusivamente a quienes tienen por vocación institucional la meditación y amor de Dios, habrá que decir que, al no tener en mente a infieles ni insensatos, su esquema teológico-doctrinal no ofrece elementos para comprender testimonios como el de Pablo de Tarso. Ante dicha problemática, una salida fácil es apelar a la doctrina de la predestinación, descontextualizando las palabras de SJC, de acuerdo con las cuales
} 
se da tal conversión?, ¿a causa y con ocasión de qué?, ¿hay algún tipo de condición sine que non de ese caer en cuenta?

En la anotación al Cántico Espiritual, SJC bosqueja una pintura de quién, a causa del encuentro con el Amado, «cae en al cuenta» o se comprende afectivamente en su ser para Dios y, al hacerlo, inicia un movimiento de conversión que lo aparta de sí para acercarlo a Aquél. El primer hallazgo de la existencia conversa es que «la vida es breve (Iob 14, 5)». En palabras de Job:

El hombre nacido de mujer, corto de días, y hastiado de sinsabores [...] sus días están determinados [...] Le pusiste límites de los cuales no pasará. Si tú lo abandonares, él dejará de ser. Entre tanto deseará, como el jornalero, su día [...] Más el hombre morirá y será cortado. Perecerá el hombre, ¿y dónde estará él? [...] Si el hombre muriere, ¿volverá a vivir? ${ }^{24}$

La finitud es el primer rasgo de su condición de ser sobre el que repara el espiritual, respecto de la cual la brevedad de la vida es una expresión disminuida. En presencia de Dios, el existente se afirma como mortal; como quien no solamente no vivirá para siempre sino que además puede hacer la experiencia aproximada de su propia extinción a través del sufrimiento por la muerte del otro - principalmente del otro amado. Aun cuando quien muere siempre es otro y por lo pronto no él, al padecer el vacío de su ausencia, el individuo reconoce su nulidad e inconsistencia. La muerte del otro es trágica porque obliga a recordar a cada uno de nosotros que en algún momento seremos ese «otro». Nos sabemos mortales cuando al padecer la muerte del otro nos replegamos sobre nuestra propia interioridad sin atrevernos a mirar lo que desearíamos ignorar: nuestra apertura preeminente e ineludible hacia un destino final que se define por el acabamiento de todo sentido en el seno de una nada enigmática que todo lo devora.

El existente es propiamente tal cuando se sabe y no sólo se piensa mortal. Cuando se apropia la capacidad de proyectarse hacia un futuro incierto sin por ello olvidar la fragilidad de toda promesa futura, incluso para con uno mismo. Cuando, ante la experiencia dolorosa de una imagen querida que se recorta del horizonte vital para siempre, acepta su desaparición irremediable. Cuando se siente embargado por la angustia de no ser más y, al par, por el absurdo que a la vuelta de la esquina o del espejo desdibuja toda proyección y atraviesa el cuerpo como un dolor sin sitio: el arrojo y la aprehensión que están en la base de nuestro apego a la existencia. Únicamente quien

\footnotetext{
«Dios pone a quien quiere y cuando quiere en el camino de la salvación». Juzgo más adecuado recordar que las guías espirituales son esquematizaciones de la experiencia mística que aportan luz general sobre dicho fenómeno. Estructuras en las cuales no puede constreñirse el acontecer efectivo del Misterio Salvífico ni la donación de la gracia; sino, en todo caso, con fines pedagógicos. A fin de no socavar la libertad de los actos divinos, de la que hablan tanto el teólogo como el místico, conviene no perder de vista que la experiencia de Dios no sigue rutas preestablecidas. Dios se encuentra con el existente que busca su presencia a solas y en silencio; le habla de modo que pueda oírle, introduciéndolo en un itinerario único.

${ }^{24}$ Job 14,$1 ; 5 ; 6 ; 10 ; 14$.
} 
se ha extraviado en el laberinto de sus propias disposiciones emocionales frente a la muerte, se comprende como finitud.

Al situarse frente a Dios, el converso descubre a un mismo tiempo su finitud y su sed de infinitud; acepta que siendo capaz de la experiencia de Dios no es divino y se reconcilia con su propia condición; asume todo lo que no es ni posee, que su vida está determinada por un término y su potencia es limitada. Evidencias que lo obligan a cuestionar el sentido de su vida para caer en la cuenta de que ha dispersado sus días y de que, en palabras de SJC, «gran parte de su vida se ha ido en el aire». Tal evidencia es el origen del dolor y contrición religiosa que describe el quebrantamiento interior de quien entiende

La grande deuda que a Dios debe en haberla criado solamente para sí, por lo cual le debe el servicio de toda su vida, y en haberla redimido solamente por sí mismo, por lo cual le debe todo el resto y respondencia del amor de su voluntad [...] y que de todo esto ha de haber cuenta y razón así de lo primero como de lo postrero, hasta el último cuadrante (Mt. 5,26), cuando escudriñará Dios a Jerusalén con candelas encendidas (Soph. 1, 12), y que ya es tarde y por ventura los postrero del día (cf. Lc. 24, 29) para remediar tanto mal y daño. ${ }^{25}$

Atraído por la presencia fascinadora del Amado y embargado por el padecer que le provoca su lejanía, de la que se sabe responsable, el converso desea la unión con Aquel a quien por tanto tiempo olvidó. Frente a Dios, el existente se sabe dependiente; sabe que el término de sus días depende de la voluntad de quien lo creó y hasta ese momento ha conservado su existencia. El origen del impulso amoroso que lo hace salir de sí en pos del rastro del Amado no es sólo el sentimiento de dependencia. Su necesidad de unión con el Amado no surge del deseo infantil de seguridad absoluta. El origen de la contrición que padece el converso ciertamente es el reconocimiento de su dependencia respecto del Amado; mas la suya es una dependencia amorosa respecto de quien por amor se encarnó, padeció y se dejó crucificar, para ofrecerle la vida eterna. A pesar de lo cual, lejos de corresponder a tal deuda amorosa, hasta antes de «caer en la cuenta» del fin sobrenatural para el cual ha sido creado, el existente no ha hecho más que vivir para sí o, en el mejor de los casos, se ha conformado con el ejercicio del amor interesado. Reconocer esto supone comprender el carácter absoluto de la gracia. La tragedia del converso reside en que, sabiendo que su misma vida es expresión de la gracia divina, quiere corresponder a ella aun cuando sabe que es del todo imposible, fundamentalmente porque la deuda del amor sobrenatural sólo se paga con el ejercicio del mismo y es asimismo don de Dios.

Si la vida obedece a un fin sobrenatural, como sostiene SJC, de ello se sigue que el existente está obligado a cooperar con lo que de suyo puede, para hacerse merecedor de la gracia que lo capacita para su realización. De ahí que la dispersión de su vida le genere culpa y arrepentimiento. La disposición afectiva engendrada por ta-

\footnotetext{
${ }^{25} \mathrm{CB}$, Anotación.
} 
les sentimientos constituye el primer paso de camino a la salvación: la apertura de una esperanza infinita en el amor incondicional del Amado que, sin merecerlo, se le ha manifestado.

Aun cuando el místico rebasa toda representación antropomórfica de Dios, en el punto inicial de su búsqueda espiritual, cuando su encuentro con Éste está todavía mediado por las representaciones tradicionales, no puede evitar hacerse una imagen finita de su creador, a quien juzga demasiado parecido a sí. Motivo por el cual teme un castigo por el incumplimiento de su deber, y se angustia pensando que si su vida terminara en un estado tan deplorable se vería privado de la gloria.

Quien busca a Dios se lamenta de que «la senda de la vida eterna [es] estrecha (Mt. 7,14$)$, que el justo apenas se salva $\left(1^{1}\right.$ Petr. 4,18$) » .{ }^{26} \mathrm{Y}$ por ello se agobia pensando que antes de su encuentro personal con el Amado, que con la mostración elusiva de su faz le ha enamorado, su capacidad infinita de amar se ha extraviado conformado con el goce de lo efímero y que por eso mismo no ha cooperado con su salvación. Quien se ha medido con Dios sabe que ante el juicio absoluto de sus actos e intenciones es imposible hallar justificación y salvación alguna a no ser que se reciba la ayuda de la gracia. «la perdición [es] muy fácil, la salvación muy dificultosa» ${ }^{27}$ porque reclama del espiritual un proceso de auto-superación para devenir semejanza del Amado, cuyo arduo camino es la imitación de Cristo. La participación en las pruebas y tentaciones por las que Éste atravesó hasta el sacrificio amoroso de sí en la cruz. Porque, como Edith Stein afirma, refiriéndose al mensaje fundamental de la teología paulina de la cruz, de la que SJC es heredero indudable:

Cristo es fuerza de Dios y sabiduría divina, no sólo en cuanto enviado de Dios, Hijo de Dios y Dios Él mismo; sino en cuanto crucificado. Y es que la muerte de Cruz es el medio de salvación escogido por la infinita sabiduría infinita. Y para demostrar que la fuerza y la sabiduría humana son incapaces de conseguir la Redención, ha sido dada la fuerza salvadora a aquello que, según las medidas humanas parece débil y loco: el que no quiere ser nada por sí mismo, sino que deja que la fuerza de Dios obre sola en él, el que se ha despojado de sí mismo y «se ha hecho obediente hasta al muerte y muerte de Cruz» ${ }^{28}$

Un hallazgo más de la existencia conversa es que «las cosas del mundo son vanas y engañosas, que todo se acaba y falta como el agua que corre $(2$ Re. 14,14$) \gg .{ }^{29}$ El mundo es vano no sólo en razón de su carácter contingente e inestable que se trasluce en las entidades efímeras, carentes de fundamento y sustento. Ante todo, lo es porque se coloca ante la mirada como una ilusión que distrae al espiritual de su fin sobrenatural. De ahí que en los inicios del proceso místico el mundo deba despreciarse

${ }^{26}$ CB Anotación.

${ }^{27}$ CB Anotación.

${ }^{28}$ E. Stein, Ciencia de la cruz. Estudio sobre San Juan de la Cruz, Monte Carmelo, Burgos, 2000, p. 46.

${ }^{29}$ CB Anotación. 
toda vez que su atención y cuidado entretienen e impiden que la atención vital se dirija a Dios y no más que a Él, por el embeleso inherente a la contemplación y el servicio de lo que, pese a su materialidad y corruptibilidad, es rastro del Amado.

Hacia el fin del camino místico el mundo se recupera bajo la perspectiva de la eternidad y perfección de la visión divina de la que el místico participa. Pero, mientras el mundo no sea más que un valle de sombras seductoras que hacen deambular de un lado a otro el deseo, debe ser rechazado. Para SJC, como para San Agustín, la búsqueda mística de Dios no es una exploración cosmológica sino un peregrinaje interior. Que por ello dice el primero:

\author{
Por toda la hermosura \\ nunca yo me perderé, \\ sino por un no sé qué \\ que se alcanza por ventura. \\ Sabor de bien que es finto, \\ lo más que puede llegar \\ es cansar el apetito \\ y estragar el paladar; \\ y así por toda la dulzura \\ nunca yo me perderé, \\ sino por un no sé qué, \\ que se halla por ventura. ${ }^{30}$
}

Como afirma San Agustín, el hombre participa de la suerte del objeto amado, de modo que al unirse por amor a tal objeto, se dirige a donde éste se encamina: a la nada, si ama las cosas efímeras; a la vida eterna, si ama a Dios como Él nos ha amado. Inmerso en la angustia por su nada de ser, el espiritual que ha accedido al encuentro con Dios se angustia no por el hecho de que su vida sea vana, sino porque libremente ha abrazado su vanidad hasta el punto de dejar de lado la correspondencia amorosa a quien por amor le ha creado y redimido, y así,

sintiendo a Dios muy enojado y escondido por haberse ella [la amada] querido olvidar tanto de El entre las criaturas; tocada ella de pavor y dolor de corazón interior sobre toda perdición y peligro, renunciando a todas las cosas, dando de mano a todo negocio; sin dilatar un día ni una hora, con ansia y gemido salido del corazón herido ya del amor de Dios, comienza [a] invocar a su Amado. ${ }^{31}$

Por obra del encuentro con el Amado, el místico se siente herido de amor, pues aun sin conocerlo ni amarlo perfectamente comprende que todo proyecto anterior es

\footnotetext{
${ }^{30}$ San Juan de la Cruz, Por toda la hermosura, versos 1-12.

${ }^{31} \mathrm{CB}$, Anotación.
} 
vano porque no puede saciar su sed infinita de amor infinito. Este es el momento más álgido de la conversión, en que el existente se propone re-orientar el amor del que es capaz para darse por entero al Amado y elige el desasimiento y desapego de sus antiguos afanes.

La observación más importante de este pasaje del Cántico Espiritual, y por ello también la más difícil de interpretar, es aquella que declara sentir «a Dios muy enojado y escondido». La representación de Dios en términos antropomórficos como alguien iracundo es simplemente una imagen poética que pone de relieve el talante personal de lo divino inherente al cristianismo, que hace de lo divino un rostro amoroso que se confronta con el individuo llamándole por su propio nombre como a un tú.

El espiritual comienza su itinerario haciendo suyas las misteriofanías y hierofanías de su tradición. Sin embargo, «lo que parece ocurrir en última instancia a lo largo del proceso místico [...] es algo particularmente interesante: a lo largo de la búsqueda puede detectarse una paulatina transformación del concepto de la deidad o, en términos más generales, de lo sagrado, a la par que una transformación en la concepción del propio sujeto de la mística». ${ }^{32}$ En los inicios de la búsqueda, quien busca a Dios en todo lo que no ha hecho por Él, lo imagina y siente muy enojado. Más tarde, al progresar en el proceso místico y superar dicha representación antropomórfica para sumergirse en el fondo abismal de un Dios que es en la medida en que acontece como amor gratuito, comprende que lo que antes percibía como enojo en Dios no era más que la decepción de sí mismo, derivada de su incapacidad y falta de compromiso para corresponder a Dios con el grado y perfección de amor con que de Él es amado. El enojo que el espiritual atribuye a Dios no es sino la proyección de su propio desencanto, provocado por la conciencia de que no ha hecho de sí un espejo finito del amor divino.

Dios no se enoja con la persona. Esta simplemente se ha separado de la vida divina, todavía definida en términos de fe (que opera mediante la caridad). Puesto que el alma se ha separado de Dios, el efecto es, empleando analogías humanas, como si se enojara Dios. Pero la causa no está en Dios, sino en el alma. El alma, al rechazar el amor de Dios no recibe la divina contemplación y, en ese sentido, sufre la ira divina. ${ }^{33}$

Mayor importancia tiene el esclarecimiento de la afirmación según la cual, para quien busca a Dios en el mundo, herido de amor, Dios está escondido. En un primer sentido, la creación natural es el sitio donde cabe suponer que Dios está escondido; el paraje que por su belleza, armonía, orden y perfección, es testimonio silente del Creador. «Por que lo invisible de Dios, desde la creación del mundo, se deja ver a la inteligencia a través de sus obras: su poder externo y su divinidad». ${ }^{34}$

${ }^{32}$ I. Cabrera, «Para comprender la mística», Umbrales de la Mistica. Cuadernos 66 (2006), p.11.

${ }_{33}$ J. Ferraro. Misticismo y compromiso en el Evangelio de San Juan vol. I, Edamex-UAM-I, México, 1997, p. 50.

${ }^{34}$ Ro $1,20$. 
Pablo y el autor de Sabiduría recuerdan cómo lo que de Dios se podía dar a conocer a las criaturas empieza a manifestarse en la creación del cosmos [...] De lo sensible, dice Pablo, es preciso llegar a lo que ya no es: a los noúmena, como se lee en el texto de Rom 1, o sea, a las realidades que sólo se entienden, partiendo de las que se sienten y nos están más cercanas. ${ }^{35}$

Sin embargo, en razón de la infinita desemejanza entre Dios y su obra, por más que la naturaleza sea «prado de verduras de flores esmaltado» donde puede leerse el rastro de Aquel que al crearlas ha derramado sobre ella «mil gracias», a partir de su percepción no es posible acceder a su experiencia clara y esencial. ${ }^{36}$ En la estructura del Cántico Espiritual, la contemplación mística de la naturaleza como reflejo de las perfecciones de Dios no acaece sino hasta las canciones catorce y quince, después que el místico ha progresado en la unión amorosa. Sólo entonces su mirada se transfigura y puede decir con verdad cuando mira en derredor: «Mi Amado las montañas, los valles solitarios nemorosos, las ínsulas extrañas, los ríos sonorosos, el silbo de los aires amorosos»».

Reconozco el valor de la monumental obra San Juan de la Cruz y el problema de la experiencia mística, de Jean Baruzi. Sin embargo, coincido con Macario Ruiz Ofilada en que

Baruzi realizó un estudio agudo del esfuerzo mistagógico por el cual se establece la hermeneuticidad, esto es, la posibilidad de intereptarse de la experiencia mística. Gracias a las categorías de la filosofía (metafísica y psicología racional) la estructura humana (psicología expermental) adquirió claridad a la luz de la experiencia mística expresada en los textos místicos. ${ }^{37}$

A diferencia del pensador francés, considero que cuando SJC habla del Amado como un «Dios sin modo», lo que con ello da a entender es la impotencia de todas las representaciones teológicas, metafísicas y psicológicas, en las cuales sigue anclada la interpretación de Baruzi, para conocer y dar cuenta del Misterio de Dios. El «Dios sin modo» de SJC es una presencia inobjetiva (como la llama Juan Martín Velasco para evitar los peligros del pensar onto-teo-lógico sobre Dios) que por amor y para el ejercicio del amor perfecto crea al hombre, a fin de ofrecerle la vida eterna, que consiste en conocer y amar a Dios como Él se conoce y ama sobrenaturalmente. Un acontecimiento gratuito, que se esencia como amor, que en virtud de su carácter sobrena-

\footnotetext{
35 M. García-Baró, «Notas sobre la mística cristiana en la perspectiva de la experiencia filosófica», Diálogo Filosófico No. 77, (2010), p. 262.

${ }^{36}$ En diversos pasajes de su obra, SJC advierte sobre la imposibilidad de recurrir al pensamiento analógico para comprender la esencia divina. Quizás, uno de los capítulos donde aborda con mayor claridad la cuestión es el capítulo ocho del segundo libro de la Subida del Monte Carmelo, titulado «Que trata en general cómo ninguna criatura ni alguna noticia que puede caer en el entendimiento le puede servir de próximo medio para la unión con Dios»».

${ }^{37}$ M. Ruiz Ofilada, S. Juan de la Cruz. El sentido experiencial del conocimiento de Dios. Claves para un acercamiento filosófico al santo Doctor, Monte Carmelo, Burgos, 2002, p. 44.
} 
tural escapa a toda representación humana, sea ésta teológica, metafísica, psicológica e incluso poética. Si lo que Baruzi sostiene es que el concepto onto-teo-lógico de Dios es propio de la teología, mas no de la teología mística ni, por ende, es apropiado para dar cuenta de la experiencia sanjuanista, coincido con él. Es una obviedad que el concepto filosófico «Dios» difiere del Dios vivo y verdadero de la revelación, cuyo encuentro da origen a la vida mística. Si, por el contrario, Baruzi interpreta la expresión sanjuanista «Dios sin modo» como queriendo significar un fondo de realidad, de carácter abismático, que por carecer de una dimensión personal tampoco podría convocar al existente a un encuentro de este tipo, por considerar que se equivoca, me distancio de él. Cristo no es una mediación prescindible en el proceso místico, ni una «figura histórica» de lo divino. El Amado cuya experiencia celebra el Cántico Espiritual es Cristo crucificado: el Dios enamorado cuya presencia fugar enamora a su esposa para unirla consigo y hacerla partícipe del ejercicio del amor perfecto propio de la vida eterna. La mística sanjuanista es cristocéntrica. Sólo cegado por el prejuicio y los excesos de la especulación filosófica, puede alguien pensar que es posible sustituir a Cristo por un abismo de realidad, y a pesar de ello afirmar sin caer en contradicción que la vida cristiana es posible, siendo la cruz de Cristo la máxima manifestación del amor que Dios es. En tal sentido, pienso que Federico Ruiz está en lo correcto cuando sostiene:

La verdad es que tampoco Baruzi había intentado realizar una interpretación completa de San Juan de la Cruz. Su intención era extraer de la síntesis sanjuanista los valores fundamentales de la religiosidad universal, de una mística sin fe, prescindiendo de los elementos específicamente cristianos. Pero, aun reduciendo el proyecto a estas proporciones, al cuestión de fondo seguía en pie: ¿Es posible realizar esa amputación metodológica sin destruir lo esencial de la doctrina sanjuanista? ${ }^{38}$

La experiencia mística de SJC no es panteísta ni supone la disolución del yo en una naturaleza sacra. Atribuir dicho carácter a la experiencia de amor místico descrita por SJC contradice uno de sus principios doctrinales al suponer que el existente puede realizar el fin sobrenatural para el cual fue creado valiéndose de medios naturales. Como bien advierte Federico Ruiz, a SJC «no le atrae la idea de lo divino, lo sublime, lo infinito, lo absoluto en abstracción. A Dios le piensa y le quiere personal y concreto. Tampoco admite rebajar a Dios a medida humana para facilitar la comprensión y el trato. Armoniza el misterio infinito con su encarnación en la persona de Cristo en vida humana». 39

El espiritual vuelto hacia Dios es el «ahí» donde habita la presencia escondida de lo divino, que el primero debe descubrir escondiéndose en sí mismo. Por ser imágenes finitas de Dios, el prójimo y el sí mismo son lugares privilegiados para manifes-

\footnotetext{
${ }^{38}$ F. Ruiz, «San Juan de la Cruz: visión mística y estética de un pensador original», Varios. Introducción a S. Juan de la Cruz, Ávila 1987, p. 55.

${ }^{39}$ F. Ruiz, Místico y maestro. San Juan de la Cruz, Editorial de Espiritualidad, Madrid, 2006, p. 148.
} 
tar su presencia. No obstante, para SJC, el existente sólo arriba al conocimiento de su propia condición de ser mediante la iluminación mística, de la que es causa la contemplación infusa amorosa. Merecer el don de la contemplación infusa reclama del individuo ejercitarse en la operación sobrenatural de las virtudes teologales, que a su vez supone la intervención de la gracia divina. Ellas son el único medio proporcionado para la realización del fin sobrenatural del ejercicio de amor perfecto. Motivo por el cual, «sin caminar a las veras con ellas es imposible llegar a la perfección de unión con Dios por amor.» ${ }^{40}$, debido a que éstas «tienen por oficio apartar al alma de todo lo que es menos que Dios y de juntarla con Él». ${ }^{41}$

Para el conocimiento del Misterio de Dios no basta la operación natural de las virtudes morales. No es el amor natural sino el sobrenatural la vía universal de la salvación. Únicamente cuando la capacidad del espiritual para ejercitarse en el conocimiento amoroso se ha dilatado hasta el orden sobrenatural, está en condiciones de reconocer en el prójimo la presencia velada de Dios, hasta el punto de amarlo y conocerlo con perfección sobrenatural.

Finalmente, por ser un factor determinante del modo de estar en el mundo del individuo, el temple o la disposición afectiva es el «dónde» que abre o cancela la posibilidad de encuentro personal con Dios. Puesto que todo comprender es afectivo, de ello se desprende la obligatoriedad de indagar qué tipo de disposición afectiva se corresponde al acto de caer en la cuenta del acontecimiento de Dios, que suscita la conversión. Se denomina «temple» o disposición afectiva al estado de ánimo de un individuo, que condiciona y determina su modo de estar en el mundo en cada caso. $\mathrm{Si}$, como sostiene Heidegger, todo comprender es afectivo, de ello se sigue que el mero proyecto de interpretar un poema místico (donde «poesía mística» no designa una forma literaria ni un «contenido» sino la expresión sonora de un comportamiento irreductible y autónomo, que se define por la espera serena del acontecimiento de lo divino) reclama del intérprete el análisis fenomenológico del temple, entendido como el «lugar poético», en cuyo seno acontece la donación de lo divino.

El habitar poético que se despliega en el seno de lo sagrado, suscitado por la donación de lo divino, es el comportamiento originario del que la poesía místico-religiosa es eco y resonancia. «La configuración rítmica del decir, empero, es determinada previamente por el temple fundamental de la poesía que se obtiene en el boceto interno del todo de su forma. El temple fundamental crece, empero, desde el respectivo lugar metafísico de cada poema». ${ }^{42}$

El temple del converso determina afectivamente su situación existencial; el horizonte hermenéutico donde tiene lugar el encuentro con el Esposo, que provoca el enamoramiento de la que entonces se constituye como «amada». De ahí que una de las

\footnotetext{
40 San Juan de la Cruz, Noche oscura, libro 2, capítulo 21, párrafo 12. En adelante me referiré a esta obra mediante la sigla $\mathrm{N}$, antecedida del número arábigo correspondiente al libro, seguida de los número de capítulo y párrafo (v.g., $2 \mathrm{~N} \mathrm{21,12).}$

$412 \mathrm{~N} 21,11$.

${ }^{42}$ M. Heidegger, , Los himnos de Hölderlin «Germania» y «El Rin», (trad. Ana Carolina Merino Riofrío), Biblioteca Internacional Martin Heidegger, Editorial Biblios, Argentina, 2010, p. 30.
} 
directrices hermenéuticas del Cántico Espiritual, si es que ha de mantenerse el propósito de conducir a la claridad del pensar filosófico la experiencia mística que en él se declara, debe ser el análisis fenomenológico de cada uno de los elementos que configuran el temple de la conversión. Sólo a partir de su dilucidación cabe comprender quién es el que, herido de amor, pregunta por el Amado y, no hallando respuesta inmediata en el sitio desde el cuál lo busca (su misma disposición afectiva), tiene que emprender el camino de la vía mística, a fin de desocultar la presencia de Aquel, mediante la purgación y el desasimiento de cuanto de Él difiere. Refiriéndose al Cántico Espiritual, Juan Martín Velasco señala:

el punto de partida es un hombre habitado por una presencia -aunque ésta tenga su primera manifestación en el padecimiento por la ausencia: «¿adónde te escondiste...?»- y movido, espoleado, orientado, atraído -con tanta más fuerza cuanto más cerca se halla de su centro de gravedad- por el amor. ${ }^{43}$

El lugar donde el Amado está escondido es la existencia misma. Mas para hallarla, el existente requiere emprender un arduo camino de desasimiento, a fin de que, aquella «presencia inobjetiva» que lo inhabita-que delata el temple contrito de la conversión- se manifieste, dando paso a la clara y esencial visión por la que, con gemidos inefables, lo llama a la presencia, preso de la desesperación. El proceso de dicho desocultamiento es la trama de las canciones de amor entre la amada y el Esposo Cristo.

\section{CONCLUSIÓN}

El habla no es la actividad de un atributo humano; es la mostración velada de la verdad del ser en su despliegue histórico. El existente sólo habla propiamente cuando se torna eco del decir del ser. A través suyo se consuma la manifestación histórica del sentido ontológico como evento. Es por ello que, preeminentemente, «verdadera» es la existencia y no la proposición.

El poema es lo hablado puro porque resguarda el eco de una experiencia originaria de encuentro entre el existente y las cosas, que en su aparecer gestan un mundo de significaciones donde se despliega el habitar cotidiano. Es la palabra generada por el habitar poético: por la disposición existencial abierta a la espontaneidad de los fenómenos del mundo, que se deja embargar por la donación de sentido ontológico.

En SJC, la palabra poética asume la forma de cántico espiritual toda vez que recoge el testimonio existencial de la manera en que la manifestación esencial de lo divino deriva en la transfiguración amorosa de quien «con ansias en amores inflamadas» avanza en pos del Amado.

El Dios del cristianismo es siempre un Dios desconocido, una manifestación a la que no puede comprenderse sino veladamente, en la experiencia contemplativa, en

\footnotetext{
43 J.M. Velasco, La experiencia cristiana de Dios, Trotta, Madrid, 2007, p. 192.
} 
virtud de su plenitud inabarcable. Tal es la primera y principal causa de su inaccesibilidad que explica el decir paradójico, temeroso y dubitativo, de los «dichos de amor en inteligencia mística» donde se recoge su aparecer fenoménico.

Uno de los problemas inherentes a la interpretación del Cántico Espiritual es que, luego de atravesar por la experiencia amorosa de unidad con el Amado Esposo Cristo, llevado por su deseo de de dar testimonio de cuanto le ha ocurrido y consciente de los límites del lenguaje ordinario, el místico se pregunta: «¿quién podrá escribir lo que a las almas amorosas donde El mora hace entender?, ¿y quién podrá manifestar con palabras lo que las hace sentir?, ¿y quién finalmente lo que las hace desear?».

En su calidad de maestro y guía espiritual, consciente de la inefabilidad de la experiencia mística, y con el propósito de situar al lector en el umbral de lo sagrado, para obligarlo a preguntarse si puede afirmar como propia la disposición afectiva de la amada que, ante el encuentro fugaz con el Esposo Cristo, ha quedado herida de amor, antes de dar paso a la declaración de las canciones del Cántico Espiritual, SJC describe esencialmente la disposición afectiva de la conversión. La intención de tal descripción es señalar la inutilidad de buscar la presencia escondida de Dios en la creación -ya sea que por ésta se entienda la naturaleza, el prójimo- o la Sagrada Escritura. La experiencia místico amorosa es encuentro personal con Dios que transforma al existente, haciéndolo capaz de realizar el fin sobrenatural para el cual fue creado. El único medio proporcionado a tal fin es la contemplación oscura amorosa, que Dios infunde por gracia en la iluminación de su Verbo.

Si el Amado está escondido en el hombre mismo, en el sentido de que el fin sobrenatural para el cuál ha sido creado es la unión de semejanza amorosa con este último, descubrir su presencia equivale a emprender un proceso de desocultamiento que tiene por origen el amor divino: es el Esposo quien, enamorando a la amada, la hace desear su presencia y buscarla de noche; quien la auxilia con su iluminación para que, participando de se sabiduría amorosa logre conformarse a su esencia; y quien, finalmente, la une consigo en matrimonio amoroso.

La poesía mística es resonancia de la vida mística; del conocimiento amoroso por fe sobrenatural, del Misterio de Dios. Por cuanto dicho conocimiento comporta no sólo una dimensión cognitiva sino que además es de orden afectivo, es forzoso comprender que el temple descrito por SJC el el prólogo y la anotación corresponde al primer momento del proceso místico: la conversión. Movimiento por obra del cual la amada se constituye como tal, por cuanto, confesando a Cristo como su Amado, funda en la palabra poética su existencia amante. 